\title{
APLIKASI PELACAKAN ALUMNI STMIK AKAKOM BERBASIS SISTEM INFORMASI GEOGRAFIS
}

\author{
Edi Iskandar ${ }^{1}$, Dini Fakta Sari \\ 1, 2Teknik Informatika STMIK Akakom \\ Jln. Raya Janti 143 Yogyakarta 55198 Telp. (0274) 486664 \\ e-mail: 1edi_iskandar@akakom.ac.id, 2 dini@akakom.ac.id
}

\begin{abstract}
Alumnus is a product of an educational institution. The quality of the alumnus shows the quality of the educational institution. The fact is increasingly felt, especially for college alumnus. This is because alumnus of college will directly come into contact with the world of work.

Tracer study activity is one of the activities that have a very strategic value in the development of a college. STMIK Akakom is one of the universities in the city of Yogyakarta is required to always mempebaiki quality of education process accompanied by efforts to increase its relevance in the framework of global competition. In addition Tracer study is one effort that is expected to provide information to evaluate educational outcomes in STMIK Akakom. This information is used for further development in ensuring educational quality.

This research produces alumnus application of STMIK Akakom alumnus by utilizing Geographic information system to map the location where alumnus work, besides that it also displays alumnus data in the form of year of admission, graduation year, long waiting time to work first after graduation
\end{abstract}

Keywords : tracking, alumnus, geographic information system..

\section{PENDAHULUAN}

Alumni merupakan produk dari suatu institusi pendidikan. Kualitas alumni menunjukkan kualitas dari institusi pendidikan tersebut. Fakta tersebut semakin terasa, khususnya untuk alumni perguruan tinggi. Hal ini dikarenakan alumni perguruan tinggi secara langsung akan bersentuhan dengan dunia kerja.

Di sisi lain, pada dasarnya masalah alumni tidak hanya terletak pada kesiapan alumni tersebut dalam mengarungi dunia baru (dunia kerja).
Bagaimana menjaga hubungan baik antar alumni, maupun antara alumni dengan almamaternya. Pada umumnya, ketika seorang mahasiswa telah lulus, hubungan ini menjadi renggang atau bahkan putus sama sekali. Tentunya dengan hubungan yang tetap terjaga akan membawa banyak manfaat baik dari sisi alumni maupun institusi pendidikan.

Kegiatan tracer study merupakan salah satu kegiatan yang mempunyai nilai sangat strategis dalam pengembangan sebuah perguruan tinggi. 
Ada banyak kasus-kasus permasalahan tentang tracer study yang berbasis Sistem Informasi Geografis dalam penentuan lokasi, dari hasil pustaka yang dilakukan, banyak ditemukan buku, tesis, paper, artikel maupun jurnal ilmiah yang membahas tentang pencarian rute terpendek dengan menggunakan algoritma tertentu, diantaranya : Bakti, dkk (2015) melakukan penelitian dengan judul Sistem Informasi Pelacakan Jejak Alumni (Tracer Study) Berbasis Smart Phone. Penelitian ini menghasilkan aplikasi pelayanan tracer study versi mobile yang mampu memberikan alternatif dalam kemudahan mengisi kuisioner bagi para alumni. Tersedianya layanan ini dapat memberikan keleluasaan waktu bagi alumni untuk melakukan pengisian kuisioner kapanpun dan dimanapun serta dapat dijadikan sumber informasi tentang kegiatan alumni dan informasi peluang karir.

Berbeda dengan Saleh (2012) melakukan penelitian dengan judul Tracer Study Alumni Fakultas Teknik Universitas Tanjungpura dengan Sistem Informasi Berbasis Web. Penelitian ini menghasilkan Sistem Informasi dan Manajemen Alumni (Simalum) yang mampu menjadi alat/media tracer alumni guna memenuhi kebutuhan data kemahasiswaan khususnya dan data alumni pada umumnya. Simalum yang dibangun merupakan media dimana antar alumni dapat saling berkomunikasi dan berbagi informasi untuk berbagai kegiatan alumni.

Yuwono (2009), melakukan penelitian dengan judul Implementasi Algoritma Koloni Semut Pada Proses Pencarian Jalur Terpendek Jalan Protokol di Kota Yogyakarta. Penelitian ini mampu memanipulasi, menganalisis, menampilkan, dan memodelkan data georeferensi untuk pemecahan suatu masalah. Salah satu permasalahan informasi keruangan adalah menentukan proses pencarian jalur terpendek jalan protokol di suatu wilayah tertentu. Metode pemodelan dalam proses pencarian jalur terpendek jalur protokol di kota Yogyakarta, dapat menampilkan informasi tiap jalurnya yang bertujuan untuk mencari jalur terpendek diantara kombinasi jalur yang diberikan serta melakukan pencarian (search) terhadap lokasi yang diinputkan oleh user.

Demikian juga penelitian yang dilakukan oleh Purba (2009), dengan judul Aplikasi Pencari Rute OptimumMenggunakan Algoritma 
Semut di Kampus Universitas Sumatera Utara dengan Dukungan Sistem Informasi Geografis. penelitian ini melakukan pengujian kepada setiap parameter algoritma semut, sehingga diperoleh bahwa parameter banyak semut dan siklus mempengaruhi probalitas dalam pencarian titik tujuan dan waktu eksekusi pencarian, parameter $\tau \mathrm{ij}, \mathrm{q} 0$ dan $\alpha$ mempengaruhi probabilitas dalam pencarian titik tujuan, sedangkan parameter $\beta$ dan $\rho$ berpengaruh dalam waktu eksekusi pencarian rute optimum. Aplikasi pencari rute optimum yang mengimplementasikan Algoritma Semut ini dibangun dengan menggunakan perangkat lunak Sistem Informasi Geografis.

Penelitian Dwidasmara (2009) dengan judul Sistem Informasi Geografis berbasis SVG untuk perjalanan Wisata dengan Dukungan Teknologi Mobile dan Pencarian Rute Terpendek dengan Algoritma Dijkstra. Penelitian ini membuat Sistem Informasi Geografis dengan memetakan daerah wisata di Bali dan mampu mencarikan rute terpendek yang bisa dilewati wisatawan yang bisa diakses lewat web dan mobile

Iskandar (2012) melakukan penelitian Sistem Informasi Geografis pemetaan daerah rawan gempa tektonik serta jalur evakuasi di Yogyakarta, dalam penelitian ini ditampilkan peta daerah rawan gempa tektonik di Yogyakarta yang terdiri dari 3 zona yaitu zona merah, zona kuning dan zona hijau, serta sistem mampu menampilkan Jalur Evakuasi korban gempa dengan rute terpendek menggunakan algoritma Dijkstra.

STMIK Akakom merupakan salah satu perguruan tinggi di kota Yogyakarta dituntut untuk selalu mempebaiki kualitas proses pendidikannya disertai dengan upaya peningkatan relevansinya dalam rangka persaingan global. Upaya yang telah dilakukan itu dimaksudkan sebagai langkah untuk memperbaiki mutu lulusan yang mampu menguasai ilmu pengetahuan dan teknologi sesuai dengan tuntutan perkembangan zaman. Guna mencapai lulusan dengan kualifikasi yang sesuai dengan kebutuhan pasar diperlukan tracer study. Hasil tracer study digunakan sebagai dasar untuk perkembangan sarana dan prasarana proses pembelajaran agar lulusannya dapat terserap di pasar kerja dengan maksimal.

Selain itu Tracer study merupakan salah satu upaya yang diharapkan dapat menyediakan informasi untuk mengevaluasi hasil pendidikan di 
STMIK Akakom. Informasi ini digunakan untuk pengembangan lebih lanjut dalam menjamin kulitas pendidikan. Dengan kegiatan tracer study diharapkan kampus mendapatkan informasi indikasi kekurangan pelaksanaan program studi dan menyediakan dasar-dasar pelaksanaan perencanaan dimasa depan. Untuk itu informasi keberhasilan profesionalisme (karier, status, pendapatan) dari para alumni sangat diperlukan. Demikian pula informasi terhadap pengetahuan dan keahlian yang relevan (hubungan antara pengetahuan dan keahlian dengan kebutuhan kerja, ruang lingkup pekerjaan, posisi professional) juga diperlukan. Para alumni diharapkan juga dapat memberikan penilaian tentang kondisi dan regulasi belajar yang mereka alami dalam masa belajar setelah dikaitkan dengan dunia kerja yang mereka hadapi.

Berdasarkan kenyataan tersebut, maka perlu suatu manajemen alumni yang dapat digunakan dalam mengelola alumni, sehingga tercipta alumni-alumni yang berkualitas dengan tetap menjaga hubungan baik dengan almamater mereka. Besarnya jumlah alumni memberikan kesempatan yang cukup luas dalam membuka peluang kerjasama, baik antara Akakom dengan alumni, alumni dengan alumni, maupun alumniAkakom-pengguna lulusan (masyarakat). Peluang ini dapat berupa penelitian, peluang lowongan pekerjaan, penawaran lulusan, pemagangan, promosi, event information dan professional directory.

\section{METODE}

\section{Aturan bisnis}

Beberapa aturan bisnis dalam rancangan basis data pada aplikasi pelacakan alumni ini adalah :

a. Admin melakukan input data halaman beranda dan update data halaman beranda, menambahkan data dan menghapus data halaman beranda

b. Admin dapat melakukan upload dan update dan menambahkan serta menghapus artikel, dimana artikel terdiri dari sub menu pengumuman, lowongan pekerjaan, dan bimbingan karir.

c. Admin dapat melakukan upload dan update dan menambahkan serta menghapus materi download.

d. Admin dapat melakukan input dan update data tracer study dan menambahkan serta menghapus data tracer studi

e. Admin dapat melakukan input dan update dan menambahkan dan 
menambahkan serta menghapus kontak kampus.

f. Admin melakukan verifikasi atas data dan informasi yang upload oleh Alumni dan Dosen, terutama pada menu Galeri Alumni, menu Artikel pada sub menu Lowongan Pekerjaan dan menu Tracer Study.

g. Alumni dapat melihat menu halaman depan.

h. Alumni dapat melihat menu artikel dan sub menu yang ada pada menu artikel, khusus sub menu lowongan pekerjaan, alumni dapat melihat dan mengupload informasi lowongan pekerjaan.

i. Alumni dapat melihat dan mengupload informasi pada Galeri Alumni.

j. Alumni dapat men-download data dan informasi yang ada pada menu Download

k. Alumni dapat melihat dan mengupload data dan informasi tracer studi

1. Alumni dapat melihat informasi kontak kampus

m. Dosen dapat melihat menu halaman depan.

n. Dosen dapat melihat menu artikel dan sub menu yang ada pada menu artikel, khusus sub menu lowongan pekerjaan, Dosen dapat melihat dan mengupload informasi lowongan pekerjaan.

o. Dosen dapat melihat dan mengupload informasi pada Galeri Alumni.

p. Dosen dapat men-download dan meng-upload data dan informasi yang ada pada menu Download

q. Dosen dapat melihat data dan informasi tracer studi

r. Dosen dapat melihat informasi kontak kampus

s. Alumni dapat melihat informasi kontak kampus

t. Dosen dapat melihat menu halaman depan.

u. Dosen dapat melihat menu artikel dan sub menu yang ada pada menu artikel, khusus sub menu lowongan pekerjaan, Dosen dapat melihat dan mengupload informasi lowongan pekerjaan.

v. Dosen dapat melihat dan mengupload informasi pada Galeri Alumni.

w. Dosen dapat men-download dan meng-upload data dan informasi yang ada pada menu Download

x. Dosen dapat melihat data dan informasi tracer studi 
y. Dosen dapat melihat informasi kontak kampus

a. Sistem dapat mengelola profil perguruan tinggi, artikel, lowongan pekerjaan, pengumuman, download center, galeri alumni dan bimbingan karir

b. Sistem digunakan untuk pendaftaran alumni

c. Sistem dapat menerima dan membalas pesan

d. Sistem dapat dipakai untuk menginputkan dan mengelola data tracer study, baik data spasial maupun data non spasial

e. Sistem dapat menerima info lowongan pekerjaan dan info lainya dari alumni dan selanjutnya admin dapat menambahkan info tersebut di sistem.

f. Sistem menyediakan navigasi yang mudah dan pencarian informasi dengan cepat dan tepat melingkupi profil alumni, lowongan pekerjaan, pengumuman dan bimbingan karir.

Selain kebutuhan funsional perlu juga didefinisikan kebutuhan non fungsional seperti kebutuhan perangkat lunak dan server webhosting agar sistem dapat berjalan dengan optimal, selain itu juga perlu didefinisikan kebutuhan keamanan dan kinerja sistem

Kebutuhan non fungsional dapat didefinisikan sebagai berikut :

1. Sistem operasi yang digunakan : Microsoft Windows 7

2. Browser

3. Sistem dilengkapi dengan otentikasi dan otorisasi untuk menjaga keamanan dari penggunaan user ilegal.

4. Sistem bersifat user friendly sehingga mudah dipahami dan digunakan.

5. Sistem bersifat stabil pada saat digunakan walaupun digunakan oleh user yang banyak dalam waktu yang bersamaan.

6. Sistem tidak pernah mengalami kegagalan pada saat menambah dan menampilkan data.

\section{Data Flow Diagram}

DFD yang dibuat dalam sistem ini mencakup tiga entitas luar yaitu admin, Dosen dan user. Data Context Diagram dapat juga disebut Diagram Aliran Data level 0. Data Context Diagram berisi penjelasan umum atau global tentang proses yang terjadi dalam sistem yang menggambarkan interaksi antara sistem dan entity luar. Berdasarkan pemahaman 
tersebut, maka Diagram Konteks dapat dilihat pada Gambar 1.

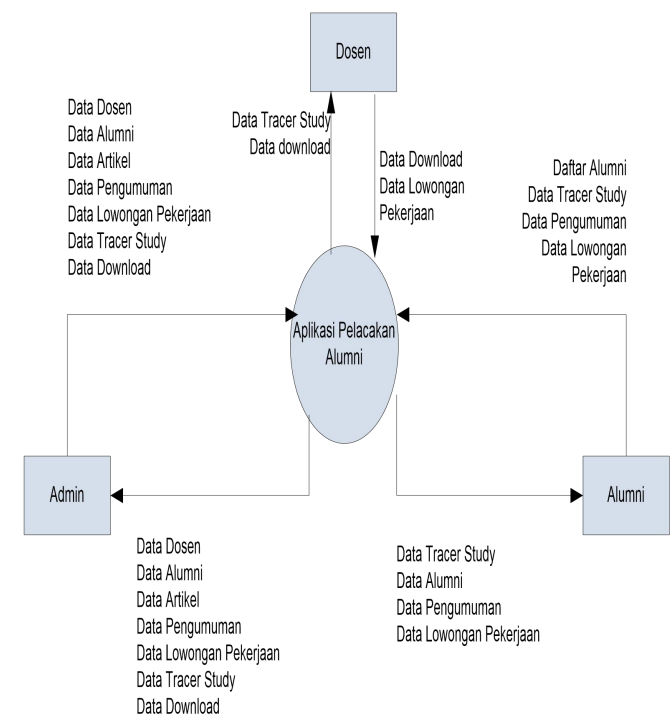

Gambar 1. Diagram Konteks

Admin melakukan transaksi data yang berupa data dosen, data alumni, data artikel, data pengumuman, data lowongan pekerjaan, data download dan data tracer studi. Administrator juga menerima data dosen, data alumni, data artikel, data pengumuman, data lowongan pekerjaan, data download dan data tracer studi.

Dosen adalah pengguna yang membutuhkan informasi lowongan pekerjaan dan data download dan dapat melakukan transaksi data download serta data lowongan pekerjaan

Alumni melakukan transaksi data yang berupa data alumni, data tracer studi, data pengumumanl, dan data lowongan pekerjaan selain itu alumni menerima data alumni, data tracer studi, data pengumumanl, dan data lowongan pekerjaan

Dari diagram pada Gambar 2, disajikan Entity Relationship Diagram yang menjelaskan hubungan antar bagian.

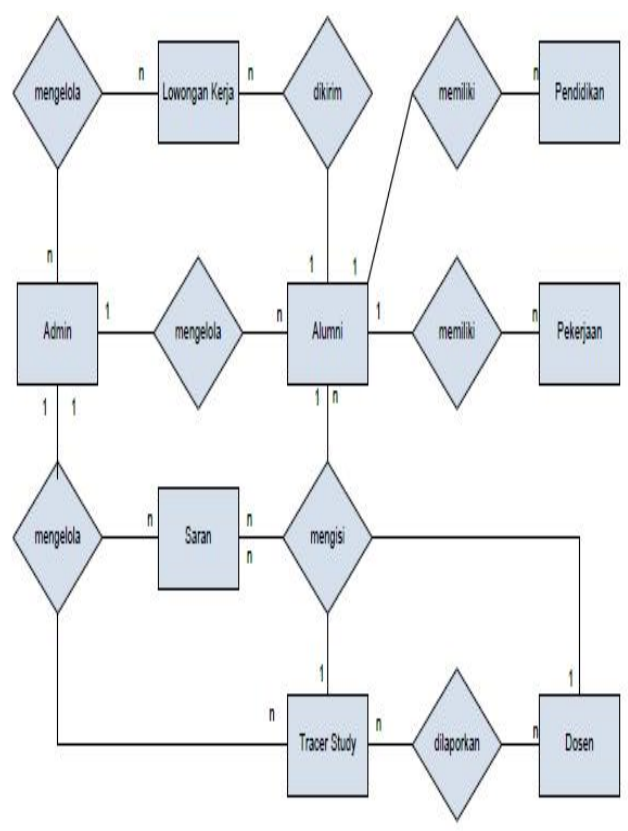

Gambar 2. ERD

\section{HASIL DAN PEMBAHASAN}

\section{Hasil Penelitian}

Implementasi Aplikasi Pelacakan Alumni berbasis Sistem Informasi Geografis ini secara umum dapat berjalan dengan baik, telah dilakukan uji coba dengan :

a. Aplikasi dapat dijalankan dengan menggunakan Browser yang telah terinstal seperti : Chrome, Mozilla 
Firefox, Safari dan Opera, uji coba telah dilakukan untuk aplikasi Admin Side dan Alumni Side serta Dosen Side dengan menggunakan browser tersebut.

b. Admin Side mempunyai kemampuan :

1) Mengolah data Beranda yang berisi data dan informasi informasi penting yang dapat dibaca oleh Alumni Side dan Dosen Side.

2) Mengolah data Artikel Berita yang berisi data dan informasi informasi penting dapat dibaca oleh Alumni Side dan Dosen Side.

3) Mengolah data Galeri Alumni dan Download yang berisi data dan informasi - informasi penting dapat dibaca oleh Alumni Side dan Dosen Side

4) Mengelola data Login Alumni

5) Mengelola Peta Alumni yang berisi peta sebaran alumni dan Mengelola Kontak Kampus

c. Dosen Side mempunyai kemampuan:

1) Melihat data Beranda yang berisi data dan informasi - informasi penting.
2) Melihat data Artikel Berita yang berisi data dan informasi informasi penting.

3) Melihat data dan foto kegiatan pada Galeri Alumni

4) Mendownload dan menambahkan informsi - informasi yang ada pada menu Download

5) Melakukan login dengan username : nama dosen dan password : NPP dosen

6) Melihat Peta Alumni yang berisi peta sebaran alumni dan Melihat Kontak Kampus

d. Alumni Side mempunyai kemampuan:

1) Melihat data Beranda yang berisi data dan informasi - informasi penting.

2) Melihat data Artikel Berita yang berisi data dan informasi informasi penting.

3) Melihat dan menambahkan data foto kegiatan alumni pada menu Galeri Alumni.

4) Mendownload informasi yang ada pada menu Download.

5) Melakukan login dengan username : nama Alumni dan password : NIM 
6) Melihat dan mengupdate data peta Alumni yang berisi peta sebaran alumni

7) Melihat Kontak Kampus

\section{Pembahasan}

Secara umum Implementasi Aplikasi pelacakan alumni berbasis Sistem Informasi Geografis yang dibangun terdiri dari beberapa menu yaitu menu Beranda, Menu Artikel Berita, Menu Galeri Alumni, Menu Download, Menu Login Alumni, Menu Peta Alumni dan Menu Kontak Kampus. Lebih detil halaman depan terlihat seperti Gambar 3.

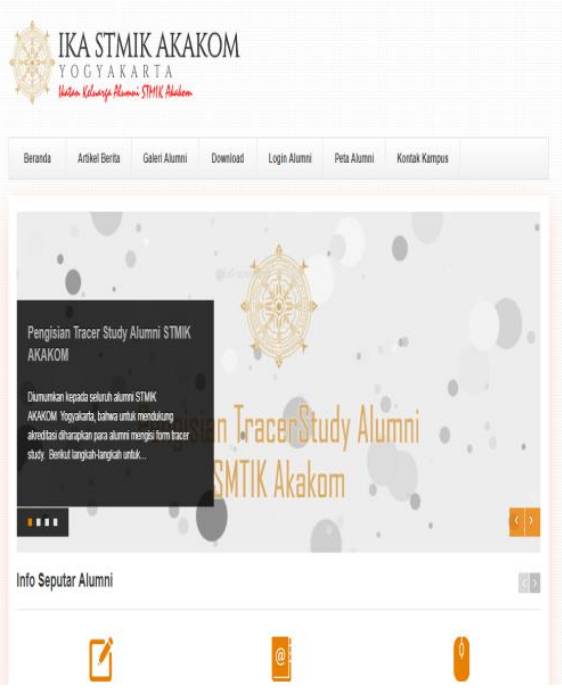

Gambar 3. Halaman Depan

Informasi lowongan Pekerjaan dapat dibuka pada menu Artikel Berita dengan memilih sub menu Lowongan Pekerjaan. Tampilan lowongan pekerjaan disajikan pada Gambar 4. 


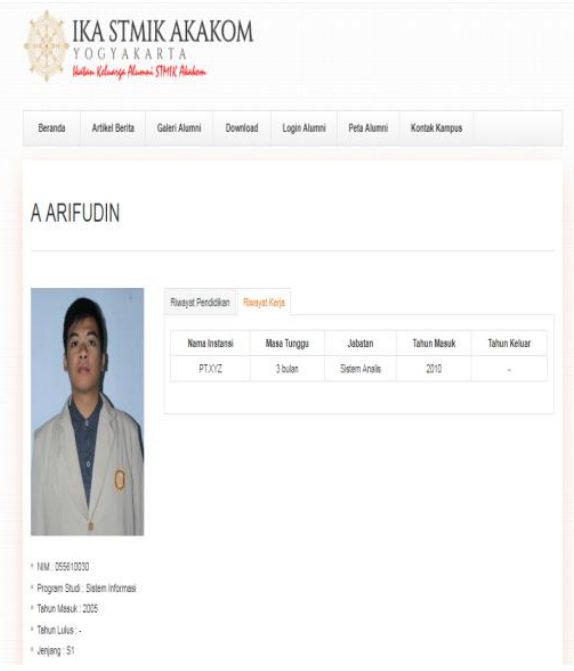

Gambar 6. Halaman Detail Alumni

Informasi sebaran alumni dapat dibuka pada menu peta alumni, peta sebaran alumni ditampilkan dalam bentuk sebaran seluruh Indonesia yang disajikan pada Gambar 7, sebaran tampilan yang bisa dipilih per provinsi, per kabupaten, per kecamatan dan per kelurahan yang disajikan pada Gambar 8 . Tampilan peta sebaran Alumni per kabupeten disajikan pada Gambar 9.

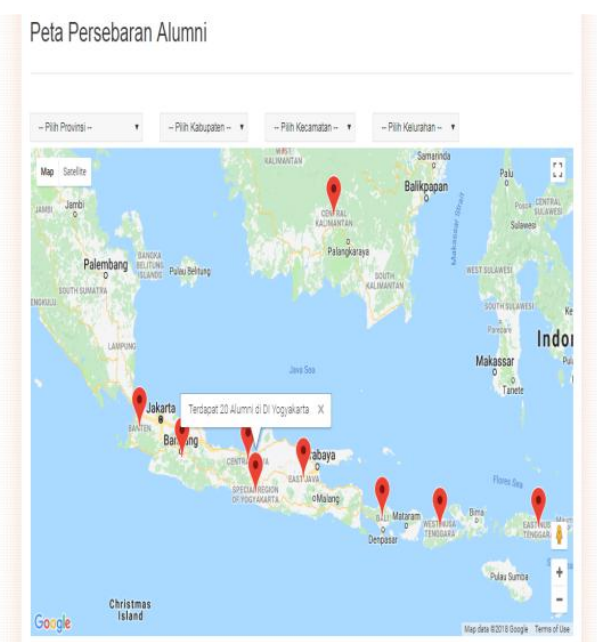

Gambar 7. Halaman Persebaran Alumni Se-Indonesia

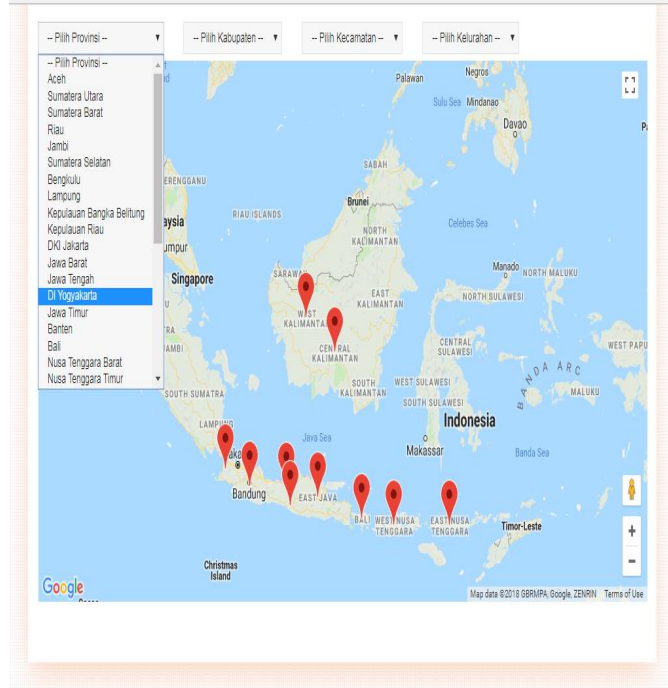

Gambar 8. Halaman Persebaran Alumni Bisa Di Pilih Per Provinsi, Per Kota / Kabupaten, Per Kecamatan, Per Kelurahan

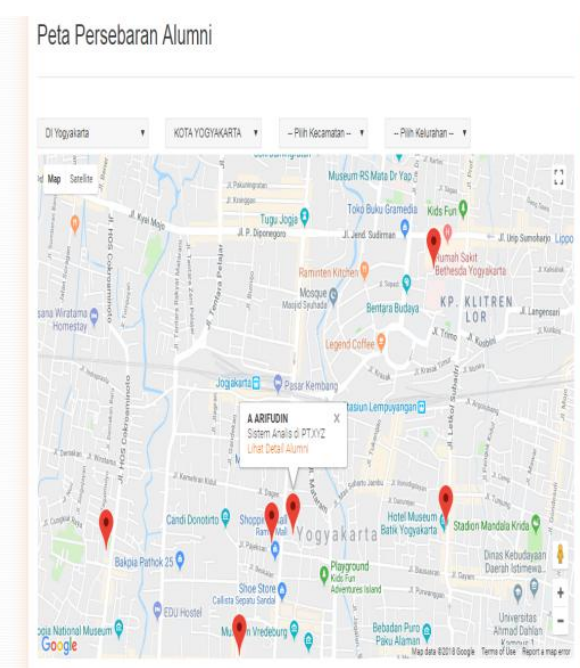

Gambar 9. Halaman Persebaran Alumni Per Kota / Kabupaten

\section{KESIMPULAN DAN SARAN}

\section{Kesimpulan}

Penelitian yang sudah dilakukan serta pembahasan pada bab-bab sebelumnya, Implementasi Aplikasi Pelacakan Alumni berbasis Sistem Informasi Geografis dapat disimpulkan bahwa : 
a. Sistem yang dibangun dapat mengelola data-data yang berhubungan dengan alumni di STMIK Akakom, sehingga kampus mempunyai database alumni yang terstruktur, aplikasi ini juga berfungsi sebagai media komunikasi antar alumni serta pusat informasi karir.

b. Aplikasi alumni memiliki model navigasi yang mudah, pengunjung juga dapat mencari informasi dengan cepat dan tepat melalui fasilitas search yang melingkupi artikel, lowongan pekerjaan dan pengumuman.

\section{Saran}

Sesuai dengan pembahasan yang diuraikan pada kesimpulan diatas, maka penulis menyarankan kepada peneliti selanjutnya untuk melengkapi penelitian ini dengan :

a. Validasi sistem informasi untuk selanjutnya dapat dilakukan penambahan metode pengujian.

b. Perangkat lunak yang dibuat sudah menggunakan template yang responsive sehingga tampilan dapat menyesuaikan lebar layar smartphone, tetapi dapat juga dikembangkan versi androidnya agar pengguna lebih nyaman lagi untuk mengaksesnya

\section{DAFTAR PUSTAKA}

Bakti, K.V., Dairoh dan Mustofa, M., 2015, Sistem Informasi Pelacakan Jejak Alumni(Tracer Study) Berbasis Smart Phone Pada Politeknik Harapan Bersama, Jurnal Teknologi Informasi dan Komunikasi, ISSN:2087-0868, Volume 6 Nomor 2 September 2015.

Dwidasmara, I.B.G, 2009, Sistem Informasi Geografis berbasis SVG untuk perjalanan Wisata dengan Dukungan Teknologi Mobile dan Pencarian Rute Terpendek dengan Algoritma Dijkstra, Tesis Program Magister Ilmu Komputer Sekolah Pasca Sarjana Universitas Gadjah Mada, Yogyakarta.

Iskandar, E., 2012, Sistem Informasi Geografis Pemetaan Daerah Rawan Gempa Tektonik serta Jalur Evakuasi di Yogyakarta, IPTEK-KOM, Volume 14, No.1, Juni 2012. 
Purba, F., 2009, Aplikasi Pencari Rute Optimum Menggunakan Algoritma Semut Di Kampus Universitas Sumatera Utara Dengan Dukungan Sistem Informasi Geografis, http://s3.amazonaws.com/academ ia.edu.documents/37464170/Frie ndly_Purba_Jurnal_Skripsi.pdf? AWSAccessKeyId=AKIAJ56TQ JRTWSMTNPEA\&Expires $=147$ $6345857 \&$ Signature $=\mathrm{aGbe} 4 \mathrm{u} 8 \mathrm{~A} 2$ 1\%2BClEANTX\%2F6aL1uraE\% 3D\&response-contentdisposition $=$ inline $\% 3 \mathrm{~B} \% 20$ filena me\%3DAPLIKASI_PENCARI_ RUTE_OPTIMUM_MENGGUN AKA.pdf 